\title{
Multifocal cavernous hemangioma of the jugular foramen: a rare skull base vascular malformation
}

\begin{abstract}
*Hussam Abou-Al-Shaar, MD, ${ }^{1}$ Yair M. Gozal, MD, PhD, ${ }^{1}$ Jason P. Hunt, MD, ${ }^{2}$ Clough Shelton, MD, ${ }^{2}$ Lyska L. Emerson, MD, ${ }^{3}$ Evan Joyce, MD, MS, ${ }^{1}$ and William T. Couldwell, MD, PhD'

'Department of Neurosurgery, Clinical Neurosciences Center; ' 2 Department of Otolaryngology-Head and Neck Surgery; and ${ }^{3}$ Department of Pathology, University of Utah, Salt Lake City, Utah

Jugular foramen cavernous hemangiomas are extremely rare vascular malformations, and, to the best of the authors' knowledge, their occurrence as multifocal lesions involving both intra- and extracranial compartments has never been reported before. Here, the authors describe the case of a 60 -year-old woman with a complex multifocal jugular foramen cavernous hemangioma. The patient presented with signs and symptoms concerning for jugular foramen syndrome, as well as a right neck mass. Surgical extirpation of the lesion was achieved by a multidisciplinary team via a right infratemporal fossa approach (Fisch type A) with concurrent high neck dissection and a closure buttressed with an autologous fat graft and a temporoparietal fascial flap. Although rare, cavernous hemangiomas should be included in the differential diagnosis of jugular foramen masses.
\end{abstract}

https://thejns.org/doi/abs/10.3171/2018.1.JNS172934

KEYWORDS cavernous hemangioma; cavernoma; cavernous angioma; multifocal; jugular foramen; infratemporal approach; vascular disorders; skull base

$\mathrm{T}$ HE jugular foramen transmits vital neurogenic and vascular structures that are of immense importance during skull base surgery. ${ }^{21}$ These neurovascular structures may give rise to a variety of lesions, most commonly glomus jugulare tumors, meningiomas, and schwannomas. ${ }^{20}$ Cavernous hemangiomas are benign vascular malformations that commonly occur as cerebral intraaxial lesions. They also frequently arise extraaxially in any vascularized tissue, including within the liver, ${ }^{9}$ skin, muscle, ${ }^{6}$ and bone, ${ }^{13,14}$ and occasionally they develop as multifocal lesions. ${ }^{19}$ The occurrence of cavernous hemangiomas in the jugular foramen, however, is extremely uncommon, with only one case previously reported. ${ }^{17}$ To the best of our knowledge, we report the first case of a multifocal cavernous hemangioma of the jugular foramen, which was treated with a radical excision via a right infratemporal fossa approach and high neck dissection.

\section{Case Report \\ Clinical Presentation}

A 60-year-old woman presented with a 9-month history of a right-sided neck mass. Although the mass remained stable in size, she developed significant right-sided suboccipital pain and neck discomfort while turning the head contralaterally. The patient also reported having progressive dysphagia and hoarseness over 3 months. She had no personal or family history of malignancy, radiation exposure, vascular malformations, or neurofibromatosis.

On examination, a soft, slightly tender, $3 \times 3-\mathrm{cm}$ mass

ABBREVIATIONS SCM = sternocleidomastoid muscle.

SUBMITTED November 21, 2017. ACCEPTED January 19, 2018.

INCLUDE WHEN CITING Published online July 6, 2018; DOI: 10.3171/2018.1.JNS172934.

${ }^{*}$ H.A.A.S. and Y.M.G. contributed equally to this work. 

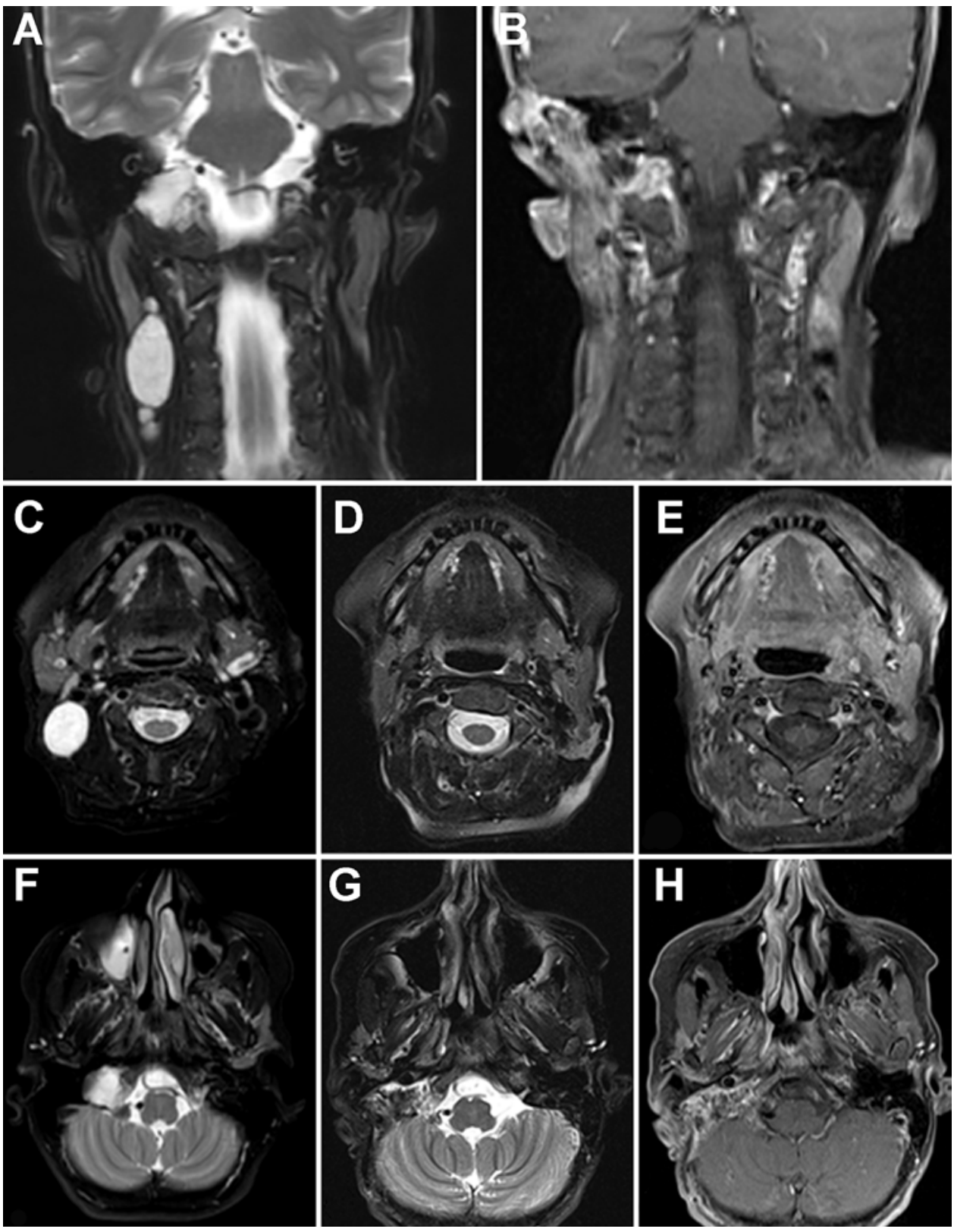

FIG. 1. Preoperative T2-weighted MR images demonstrating a hyperintense lesion in the region of the jugular foramen as well as several vertically aligned lesions in the neck under the SCM (A: coronal; C and F: axial). Postoperative T1-weighted (B: coronal; $\mathrm{E}$ and $\mathrm{H}$ : axial) and T2-weighted (D and G: axial) MR images demonstrating gross-total resection of the masses in the jugular foramen and in the neck.

was noted in the upper third portion of the sternocleidomastoid muscle (SCM) on the patient's right side. There was wasting of the right SCM and trapezius muscle, deviation of the uvula to the left, and decreased pharyngeal sensation on the right side, while the patient's gag reflex was intact. The remaining clinical findings were unremarkable. After examination of two fine-needle aspirates from the primary neck mass did not provide a diagnosis, the patient underwent an open biopsy; the findings were consistent with a cavernous hemangioma.

\section{Imaging Studies and Laboratory Evaluation}

Brain gadolinium-enhanced MRI and brain and neck contrast-enhanced CT scanning depicted a heterogeneously enhancing, right-sided lesion expanding the right jugular foramen and compressing the jugular bulb. The lesion had a small intracranial component, displaced the facial nerve in the fallopian canal laterally, and abutted the vertical segment of the petrous carotid artery. The lesion additionally appeared to involve the anterior and inferior parts of the right occipital condyle and the ipsilateral anterior arch of $\mathrm{Cl}$, and it extended into the neck under the right-sided SCM in a multifocal fashion (Fig. 1). Notably, digital subtraction angiography performed preoperatively demonstrated a patent but significantly stenosed jugular bulb with dominant contralateral venous outflow. 


\section{Operation}

The patient was positioned supine, and a right-sided Cshaped incision was made $4.5 \mathrm{~cm}$ posterior to the postauricular crease. The incision was extended 2 fingerbreadths below the inferior border of the mandible, allowing the neck dissection to be performed. After the tail of the parotid gland was elevated off the anterior border of the SCM, a T-shaped incision was made at the temporal line and the anterior border of the SCM. A temporalis fascial flap was elevated, and it was left pedicled to the anterior branch of the superficial temporal artery. The mastoid was exposed, and the SCM and posterior digastric attachments to the mastoid tip were removed. The styloid process was then identified superiorly, and the tip was removed. The dissection continued inferiorly until the omohyoid muscle was identified, marking the inferior border of the exposure. The internal carotid artery, internal jugular vein, and cranial nerves IX, X, XI, and XII were each dissected and exposed up to the skull base. A large nodal mass and multiple smaller subscalene masses were resected. Finally, having confirmed adequate contralateral venous outflow on preoperative angiography, we suture ligated the internal jugular vein distal to the inferior extension of the mass.

Attention was then turned to the mastoid, where a standard mastoidectomy was performed with a high-speed drill and the sigmoid sinus exposed. The facial recess was opened and the incudostapedial joint divided. The facial nerve was then skeletonized to the stylomastoid foramen. After additional drilling of the osseous external auditory canal and removal of the mastoid tip, the retrofacial air cells were removed and the jugular bulb exposed. The facial nerve was then transposed and held in place with a cuff of muscle in a tensionless fashion. At this point, the jugular vein was brought through the foramen. After occlusion of the sigmoid sinus with Surgicel, the tumor was progressively debulked to expose the presigmoid dura. The posterior fossa dura was opened, allowing the identification of the right vertebral artery as well as cranial nerves IX, $X$, and XI. There was no evidence of intradural extension of the mass.

At the completion of tumor removal, abdominal fascia was grafted to patch the dural opening. The facial nerve was repositioned, the eustachian tube was plugged, and the mastoid defect was packed with abdominal fat. The previously harvested temporoparietal facial flap was laid over the abdominal fat graft to cover the mastoid. The wound was then closed in layers in a standard fashion (Video 1).

VIDEO 1. Operative video demonstrating resection of a multifocal cavernous hemangioma involving the jugular foramen and right neck. Copyright Department of Neurosurgery, University of Utah. Published with permission. Click here to view.

Finally, a lumbar drain was placed to deter pseudomeningocele formation.

\section{Pathology}

Gross examination of the multiple resected lesions in the neck and that of the jugular foramen revealed relatively well-circumscribed red-tan masses, which on cut section varied from tan-red to dark red. Histological examination showed numerous dilated, blood-filled vascular spaces with relatively uniform, mildly thickened walls lined by

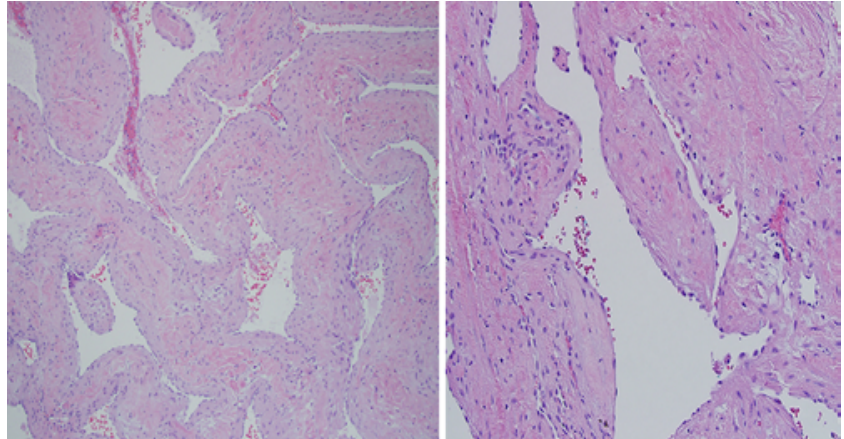

FIG. 2. Multiple dilated, blood-filled vessels (left) lined by flattened endothelium (right). $H$ \& E, original magnification $\times 100$ (left) and $\times 200$ (right). Figure is available in color online only.

flattened endothelial cells, consistent with cavernous hemangioma (Fig. 2). Only rare organizing thromboses were noted. No evidence of atypia or malignancy was present.

\section{Postoperative Course and Follow-Up}

Postoperatively, the patient was at her neurological baseline with the exception of hypophonic speech and mild dysphagia, which was worse when eating breads and meats. Flexible laryngoscopy revealed reduced right vocal fold mobility, incomplete right-sided palatal closure, and abnormal pooling of secretions in the hypopharynx bilaterally. The lumbar drain was maintained for 5 days, and the patient was discharged home on postoperative day 8 . At her last follow-up appointment 2 months after surgery, the patient was doing well, although she continued to experience pharyngeal weakness and hypophonia, ultimately requiring an injection laryngoplasty.

\section{Discussion}

The jugular foramen is an important anatomical landmark that encompasses vital neurovascular structures. ${ }^{21}$ Not uncommonly, a tumor can arise within the jugular foramen and impinge on adjacent neurovascular structures, giving rise to lower cranial nerve neuropathies. Known as jugular foramen syndrome, these neuropathies typically involve cranial nerves IX, X, and XI, although $30 \%$ of the cases additionally involve the hypoglossal nerve., $4,7,20$ Glomus jugulare paragangliomas are the most commonly encountered tumors within the jugular foramen. ${ }^{20}$ Other less frequently encountered lesions include meningiomas, schwannomas, aneurysmal bone cysts, cholesteatomas, chondromas, and inflammatory granulomas. ${ }^{20}$ Radiological imaging of these lesions not uncommonly overlaps. ${ }^{17,20}$ Thus, definitive diagnosis often requires formal histopathological examination.

Hemangiomas are classified into 3 distinct categories: capillary, cavernous, and mixed. The former usually occurs in children and obliterates spontaneously, ${ }^{24,26}$ while the latter two pathological subtypes tend to persist, becoming symptomatic via hemorrhage or mass effect on surrounding structures. ${ }^{24,26}$ Cavernous hemangiomas constitute $5 \%-13 \%$ of all vascular lesions in the brain and spinal cord. ${ }^{16,23}$ They are endothelial-lined, grossly dilated (cavernous), thin-walled vascular malformations that lack the 
tight junctions, elastic tissue, and muscle typical of normal blood vessels. ${ }^{24,26}$

Cavernous hemangiomas most commonly arise in the central nervous system parenchyma. ${ }^{16,23}$ Less frequently, they have been reported in the tentorium, skull bones, skull base, infratemporal fossa, anterior jugular vein, carotid sheath, petrosal sinus, falx cerebri and convexity dura, cerebellopontine angle, Meckel's cave, and cranial nerves. ${ }^{1-3,5,8,12,13,15,18,19,25}$ Notably, Menzel and Denecke ${ }^{17}$ described the first and only case to date of a cavernous angioma of the jugular foramen in a 51-year-old woman who presented with jugular foramen syndrome. As in the current patient, imaging demonstrated enlargement of the right jugular foramen with compression of the jugular bulb. Surgical extirpation was achieved via a radical mastoidectomy with concurrent high neck dissection. At the 6-month follow-up, the authors reported complete functional recovery of cranial nerves IX and X with residual accessory nerve paresis.

Surgical resection of symptomatic cavernous hemangiomas remains the primary management option. In quiescent lesions, where impingement of adjacent neurovascular structures is often absent, a conservative approach with observation and radiological surveillance is acceptable, ${ }^{18,22}$ particularly when aggressive therapy of the lesion may result in untoward neurological sequelae. The role of radiation therapy in the management of cavernous hemangiomas is controversial. The current literature lacks evidence-based results regarding appropriate application and therapeutic efficacy among these patients. Moreover, while radiosurgical treatment of cavernous hemangiomas located in high-risk eloquent areas has been shown to reduce rehemorrhage rates, there are no data demonstrating significant lesion regression or improvement in mass effect-related symptoms. ${ }^{10,11}$ Given the potential radiationassociated morbidity, we do not advocate for the routine use of radiation among symptomatic patients.

To the best of our knowledge, there have been no previous reports of a multifocal cavernous hemangioma involving the jugular foramen. Similar to the case presented by Menzel and Denecke, ${ }^{17}$ our patient had an extremely rare presentation of jugular foramen syndrome secondary to a cavernoma. While the lesions in both cases enlarged the jugular foramen and obstructed flow in the jugular bulb, in the current case, the lesion was multifocal in nature with extensive extracranial involvement. Surgical extirpation, with attempts to limit consequent cranial neuropathies, is recommended.

\section{Acknowledgments}

We would like to thank Kristin Kraus, MSc, for her contribution to manuscript editing and Vance Mortimer for his contribution to preparing the video.

\section{References}

1. Abou-Al-Shaar H, Bahatheq A, Takroni R, Al-Thubaiti I: Optic chiasmal cavernous angioma: a rare suprasellar vascular malformation. Surg Neurol Int 7 (Suppl 18):S523-S526, 2016

2. Andreano M, Romagnuolo G, D’Ambrosio V, La Rocca F, Zito ES, Festa P, et al: [Anterior jugular vein cavernoma in a forthcoming rupture stage: a case report.] Ann Ital Chir 76:485-489, 2005 (Ital)

3. Antonopoulos C, Karagianni M, Zolindaki C, Anagnostou E, Vagianos C: Cavernous hemangioma of infrahyoid carotid sheath and review of the literature on carotid sheath tumors. Head Neck 31:1381-1386, 2009

4. Binns PM, Fairman HD: Lesions in the temporal bone causing multiple nerve damage. J Laryngol Otol 80:125-137, 1966

5. Biondi A, Clemenceau S, Dormont D, Deladoeuille M, Ricciardi GK, Mokhtari K, et al: Intracranial extra-axial cavernous (HEM) angiomas: tumors or vascular malformations? J Neuroradiol 29:91-104, 2002

6. Bucci T, De Giulio F, Romano A, Insabato L, Califano L: Cavernous haemangioma of the temporalis muscle: case report and review of the literature. Acta Otorhinolaryngol Ital 28:83-86, 2008

7. Castellano F, Ruggiero G: Meningiomas of the posterior fossa. Acta Radiol Suppl 104:1-177, 1953

8. Fehlings MG, Tucker WS: Cavernous hemangioma of Meckel's cave. Case report. J Neurosurg 68:645-647, 1988

9. Hoekstra LT, Bieze M, Erdogan D, Roelofs JJ, Beuers UH, van Gulik TM: Management of giant liver hemangiomas: an update. Expert Rev Gastroenterol Hepatol 7:263-268, 2013

10. Karlsson B, Kihlström L, Lindquist C, Ericson K, Steiner L: Radiosurgery for cavernous malformations. J Neurosurg 88:293-297, 1998

11. Kim DG, Choe WJ, Paek SH, Chung HT, Kim IH, Han DH: Radiosurgery of intracranial cavernous malformations. Acta Neurochir (Wien) 144:869-878, 2002

12. Kornfehl J, Gstöttner W, Kontrus M, Sedivy R: Transpalatine excision of a cavernous hemangioma of the infratemporal fossa. Eur Arch Otorhinolaryngol 253:172-175, 1996

13. Liu JK, Burger PC, Harnsberger HR, Couldwell WT: Primary intraosseous skull base cavernous hemangioma: case report. Skull Base 13:219-228, 2003

14. Marcinow AM, Provenzano MJ, Gurgel RK, Chang KE: Primary intraosseous cavernous hemangioma of the zygoma: a case report and literature review. Ear Nose Throat J 91:210, 212, 214-215, 2012

15. Matias-Guiu X, Alejo M, Sole T, Ferrer I, Noboa R, Bartumeus F: Cavernous angiomas of the cranial nerves. Report of two cases. J Neurosurg 73:620-622, 1990

16. McCormick WF, Hardman JM, Boulter TR: Vascular malformations ("angiomas") of the brain, with special reference to those occurring in the posterior fossa. J Neurosurg 28:241-251, 1968

17. Menzel J, Denecke HJ: Angioma of the jugular foramen. Case report. Acta Neurochir (Wien) 53:117-122, 1980

18. Meyer FB, Lombardi D, Scheithauer B, Nichols DA: Extraaxial cavernous hemangiomas involving the dural sinuses. J Neurosurg 73:187-192, 1990

19. Peterson DL, Murk SE, Story JL: Multifocal cavernous hemangioma of the skull: report of a case and review of the literature. Neurosurgery 30:778-782, 1992

20. Ramina R, Maniglia JJ, Fernandes YB, Paschoal JR, Pfeilsticker LN, Neto MC, et al: Jugular foramen tumors: diagnosis and treatment. Neurosurg Focus 17(2):E5, 2004

21. Roche PH, Mercier P, Sameshima T, Fournier HD: Surgical anatomy of the jugular foramen. Adv Tech Stand Neurosurg 33:233-263, 2008

22. Shibata S, Mori K: Effect of radiation therapy on extracerebral cavernous hemangioma in the middle fossa. Report of three cases. J Neurosurg 67:919-922, 1987

23. Simard JM, Garcia-Bengochea F, Ballinger WE Jr, Mickle JP, Quisling RG: Cavernous angioma: a review of 126 collected and 12 new clinical cases. Neurosurgery 18:162-172, 1986 
24. Stal S, Hamilton S, Spira M: Hemangiomas, lymphangiomas, and vascular malformations of the head and neck. Otolaryngol Clin North Am 19:769-796, 1986

25. Sundaresan N, Eller T, Ciric I: Hemangiomas of the internal auditory canal. Surg Neurol 6:119-121, 1976

26. Williams HB: Hemangiomas and lymphangiomas. Adv Surg 15:317-349, 1981

\section{Disclosures}

The authors report no conflict of interest concerning the materials or methods used in this study or the findings specified in this paper.

\section{Author Contributions}

Conception and design: Couldwell, Abou-Al-Shaar, Gozal. Acqui- sition of data: Abou-Al-Shaar, Gozal. Analysis and interpretation of data: all authors. Drafting the article: Abou-Al-Shaar, Gozal. Critically revising the article: all authors. Reviewed submitted version of manuscript: all authors. Approved the final version of the manuscript on behalf of all authors: Couldwell.

\section{Supplemental Information}

Videos

Video 1. https://vimeo.com/260242618.

\section{Correspondence}

William T. Couldwell: Clinical Neurosciences Center, University of Utah, Salt Lake City, UT. neuropub@hsc.utah.edu. 